CAP patients (23\%): in CURB $<3$ iv antibiotic use reduced to $50 \%$.

Conclusion COPD patients commonly present acutely with ECOPD, NIECOPD or CAP. This can cause diagnostic uncertainty in an AMU setting. A right care approach focusing on accurate diagnosis first time and guideline based therapy, supported by joint working, education and electronic prescribing can improve staff knowledge and patient management.

\section{P93 SUPPORTING PATIENT INVOLVEMENT IN SERVICE DEVELOPMENT: ELICITING PATIENT-CENTRED INFORMATION TO INFORM COMMISSIONING OF COPD SERVICES}

${ }^{1} \mathrm{~F}$ Early, ${ }^{1} \mathrm{~T}$ Watts, ${ }^{1} \mathrm{~K}$ Homan, ${ }^{2} \mathrm{~A}$ Green, ${ }^{3} \mathrm{M}$ Brookes, ${ }^{1} \mathrm{f}$ Fuld. ${ }^{1} \mathrm{C}$ ambridge University Hospitals NHS Foundation Trust, Cambridge, UK; ${ }^{2}$ British Lung Foundation, London, UK; ${ }^{3}$ Cambridgeshire and Peterborough CCG, Cambridge, UK

\subsection{6/thoraxjn-2014-206260.234}

Introduction Patient involvement in population level health care decisions often involves consultation rather than interactive decision-making. Lack of insight into appropriate methods is a barrier to patient involvement.

Working Together for Change (WTfC) is a person-centred process to inform service development. Information from person-centred reviews (PCRs) is themed in a two-day co- production workshop. It is effective in social care and mental health but has not been applied in physical health. We tested its feasibility to improve the quality of person-centred information for COPD commissioners and of patient involvement.

Methods Forty COPD patients recruited from GP lists, secondary care and support groups participated in one-to-one PCRs. PCRs identified their priorities for what's working in their life regarding COPD, what's not working, what's important to the future.

These patients, health service professionals and third sector organisations involved in COPD support were then invited to attend the two one-day workshops. Patients' priorities were themed collaboratively. Root cause analysis of what was not working was followed by statements of what success would look like if root causes were addressed. Action plans were created.

Qualitative data from workshop observations and participant interviews were analysed using thematic analysis.

Results Service priorities included information, holistic care, access, dietary support, access to patient information for HCPs.

The improved quality of the person-centred information was evident in the ways in which professionals' understanding of patient needs was enhanced through close, informal interaction with patients and carers, e.g. witnessing difficulties such as simultaneously eating and breathing and other physical limitations that prevent patients following healthcare advice (Table 1).

Participation was positive for patients and professionals (Table 1) experiencing it as engaging and collaborative. Patients felt

\begin{tabular}{|c|c|}
\hline \multicolumn{2}{|c|}{ Enhanced understanding by professionals of patient needs and aspirations (in both breadth and depth) } \\
\hline Sub-themes & Description \\
\hline New insights & $\begin{array}{l}\text { There was surprise among professionals at some of the issues highlighted that they were not previously aware of or of which they had not appreciated the impor- } \\
\text { tance. This included a greater understanding of why, due to practical or physical limitations, patients cannot always follow the medically advised course of action } \\
\text { and mental health aspects of COPD. }\end{array}$ \\
\hline \multicolumn{2}{|l|}{ Firsthand knowledge 'from the } \\
\hline $\begin{array}{l}\text { horse's } \\
\text { mouth' }\end{array}$ & $\begin{array}{l}\text { Through close interaction professionals could hear the issues that patients had and the changes they wanted made and could see the reality of their lives and the } \\
\text { issues they dealt with (e.g. using oxygen, eating and breathing and moving around). The impact was emotional and humbling. }\end{array}$ \\
\hline $\begin{array}{l}\text { Appreciation of the range of } \\
\text { patient experience }\end{array}$ & $\begin{array}{l}\text { This was achieved through interaction with patients with a range of disease severity from mild to more severe and hearing of their differing challenges and } \\
\text { experiences. }\end{array}$ \\
\hline Hearing hard to reach voices & The process included the voices (either personally present or through PCRs) of patients who would not typically attend a focus group or consultation event. \\
\hline Varied perspectives & Having a greater number of patients present elevated the patient input from token representation to a meaningful voice. \\
\hline \multicolumn{2}{|c|}{ Positive experience of participation for patients and professionals } \\
\hline Sub-themes & Description \\
\hline \multicolumn{2}{|l|}{ Collaboration, inclusivity } \\
\hline and egalitarianism & Participants enjoyed working with each other in a pleasant, friendly atmosphere, with openness and sharing. \\
\hline Mutual understanding & $\begin{array}{l}\text { This came through mutual learning amongst both patients and professionals, seeing people's reality and hearing a range of perspectives from a variety of partici } \\
\text { pants. Patients learned about commissioning and professionals learned about the reality of patients' and carers' lives. }\end{array}$ \\
\hline Engaging and stimulating & Active engagement helped by strong facilitation (not just sitting listening). \\
\hline Freedom for ideas to emerge & There was no pre-determined end point and anonymous voting gave a sense of freedom. \\
\hline Power to make a contribution & Patients felt they were contributing to a process that could result in something influential. \\
\hline Being heard & Patients felt that all information was precious and their issues were not "lost" or "dropped" even if they did not end up in the final outcomes. \\
\hline \multicolumn{2}{|l|}{ Problems with participation } \\
\hline Sub-themes & Description \\
\hline Confusion & In the early stages of the workshop it took a while for some participants to fully comprehend the process. \\
\hline Dot voting & Some participants felt this encouraged herd mentality \\
\hline Physical difficulties & Some patients experienced mobility difficulties in a building with long corridors \\
\hline \multicolumn{2}{|c|}{ Immediate benefits to patients from taking part } \\
\hline Sub-themes & Description \\
\hline $\begin{array}{l}\text { Learning about support and } \\
\text { resources and treatments }\end{array}$ & $\begin{array}{l}\text { This came from material presented and discussed at the workshop, and from interactions with professionals. This could have a bigger impact than leaflets or } \\
\text { literature. }\end{array}$ \\
\hline Peer support & Reassurance from knowing that other people have similar issues and the opportunity to share these. \\
\hline
\end{tabular}


both heard and empowered and felt all the information they offered was precious.

Discussion Patients found it a powerful experience and felt they made a contribution for the future. Professionals gained emotional and practical insights which inspired motivation for change in service delivery. The process tapped into strong motivations for mutual understanding. It is an effective element in developing person-centred COPD services and is transferable to other LTCs.

Supported by grant from the Health Foundation

\section{P94 PATIENT AGENDA SETTING AND CLINIC EFFICIENCY IN OUTPATIENTS: AN INDIVIDUAL RANDOMISED CONTROLLED TRIAL}

A Everden, F Early, K Homan, J Fuld. Cambridge University Hospitals NHS Foundation Trust, Cambridge, UK

\subsection{6/thoraxjnl-2014-206260.235}

Introduction Most patients have issues to raise in a consultation but may not actually raise them, adversely affecting the consultation outcome. Evidence suggests that methods to help patients consider their information needs before a consultation can increase satisfaction without increasing consultation length but there is a need to assess a wider range of outcome measures and to measure consultation length accurately.

We studied the impact of a paper agenda form to prompt question asking in a respiratory outpatient clinic. The primary objective was to identify whether this increased agreement that "My doctor discussed the issues that were important to me". Secondary endpoints included consultation length and post-consultation confidence to self-manage (0-10 scale).

Method Patients were randomised to receive the agenda form or usual care by blocked randomization (block size 6), stratified by consultant. Patients receiving the form had a written brief inviting them to complete it in the waiting room.

PROMs were collected post-consultation. Consultations were timed by an observer outside the room. As planned in the protocol, categorical data were analysed using Fisher's exact test and continuous data were analysed using a t-test. Exploratory

\begin{tabular}{|c|c|c|c|c|}
\hline & & $\begin{array}{l}\text { Agenda } \\
\text { form } N=83\end{array}$ & $\begin{array}{l}\text { Usual care } \\
\mathbf{N}=\mathbf{8 0}\end{array}$ & P-value \\
\hline My doctor discussed the issues & SD* $^{*}$ & $1(1.2 \%)$ & & \\
\hline that were important to me & $\begin{array}{l}\text { A } \\
\text { SA }\end{array}$ & $\begin{array}{l}17(20.5 \%) \\
63(75.9 \%)\end{array}$ & $\begin{array}{l}21(26.3 \%) \\
56(70.0 \%)\end{array}$ & 0.4567 \\
\hline $\begin{array}{l}\text { I raised with my doctor the issues } \\
\text { that were important to me }\end{array}$ & $\begin{array}{l}\text { SD } \\
\text { A } \\
\text { SA }\end{array}$ & $\begin{array}{l}1(1.2 \%) \\
21(25.3 \%) \\
57(68.7 \%)\end{array}$ & $\begin{array}{l}18(22.5 \%) \\
59(73.8 \%)\end{array}$ & 0.6464 \\
\hline $\begin{array}{l}\text { I got the outcome I wanted from } \\
\text { my consultation }\end{array}$ & $\begin{array}{l}\text { SD } \\
\text { D } \\
\text { A } \\
\text { SA }\end{array}$ & $\begin{array}{l}1(1.2 \%) \\
2(2.4 \%) \\
18(21.7 \%) \\
58(69.9 \%)\end{array}$ & $\begin{array}{l}2(2.5 \%) \\
24(30.0 \%) \\
50(62.5 \%)\end{array}$ & 0.4591 \\
\hline $\begin{array}{l}\text { How confident do you feel that you can } \\
\text { take steps to manage your condition } \\
\text { as a result of today's visit? (0-10) }\end{array}$ & $\begin{array}{l}n \\
\text { Mean (SD) } \\
\text { Median } \\
\text { Min, Max }\end{array}$ & $\begin{array}{l}79 \\
8.7(1.92) \\
10 \\
3,10\end{array}$ & $\begin{array}{l}73 \\
8.7(1.34) \\
9 \\
5,10\end{array}$ & 0.795 \\
\hline Consultation duration (mins) & $\begin{array}{l}\mathbf{n} \\
\text { Mean (SD) } \\
\text { Median } \\
\text { Min, Max }\end{array}$ & $\begin{array}{l}83 \\
15.2(7.69) \\
13 \\
3,40\end{array}$ & $\begin{array}{l}78 \\
15.3(7.98) \\
14.8 \\
2,44\end{array}$ & 0.908 \\
\hline $\begin{array}{l}\text { *SD (Strongly Disagree) } \\
\text { D (Disagree) } \\
\text { A (Agree) } \\
\text { SA (Strongly Agree) }\end{array}$ & & & & \\
\hline
\end{tabular}

analyses to assess the effects of a number of factors used mixed model ANOVA.

Results Groups were well matched at baseline for age, gender and respiratory diagnosis. There was no significant effect of agenda form use on the primary or secondary endpoints (Table 1). Exploratory analyses identified that in new patients (but not in follow-up patients) the form was associated with shorter consultation length (LS mean $=15.2$ mins) than usual care (LS mean $=21.3$ mins) $(\mathrm{p}=$ $0.017)$ and with lower confidence to self-manage (LS mean=6.6) than usual care (LS mean=9.2) $(\mathrm{p}=0.001)$.

Conclusion There was no overall benefit from the form and a risk of detrimental impact on patient experience for some patients. This resonates with reports from other more complex self-management interventions that have found unexpected detrimental effects in some patients. There is a need for greater understanding of what works for whom with regard to self-management support. It cannot be assumed that the impact will be universally beneficial at best or neutral at worst.

\section{REFERENCE}

1 Trial reference: REC reference: 13/WA/0171

\section{P95 NON CF BRONCHIECTASIS}

CJ Baggott, E Harris, I Suntharalingam, AS Malin. Royal United Hospitals Bath, Bath, UK

\subsection{6/thoraxjnl-2014-206260.236}

Background Bronchiectasis is said to affect 100/100 000, however the true prevalence is probably significantly higher. Our previous BTS bronchiectasis audit identified that a significant service improvement was required. This led to the introduction of a home intravenous antibiotic pilot, a bronchiectasis working group, and enhanced teaching and information sharing with primary care. Despite this, these patients remain poorly served both in the community and hospital.

From 2009-13 there were 330 bronchiectasis admissions to our hospital. A significant proportion of these could have been managed in the community, substantially reducing the cost to the NHS. Aims We are developing an integrated bronchiectasis service between hospital and community. The vision has been to create a primary and secondary care interface, utilising the usual multidisciplinary team plus psychology and dietetic support, a 'hospital without walls' model and an online, multi-faceted communication tool.

\section{Integrated bronchiectasis care pathway}

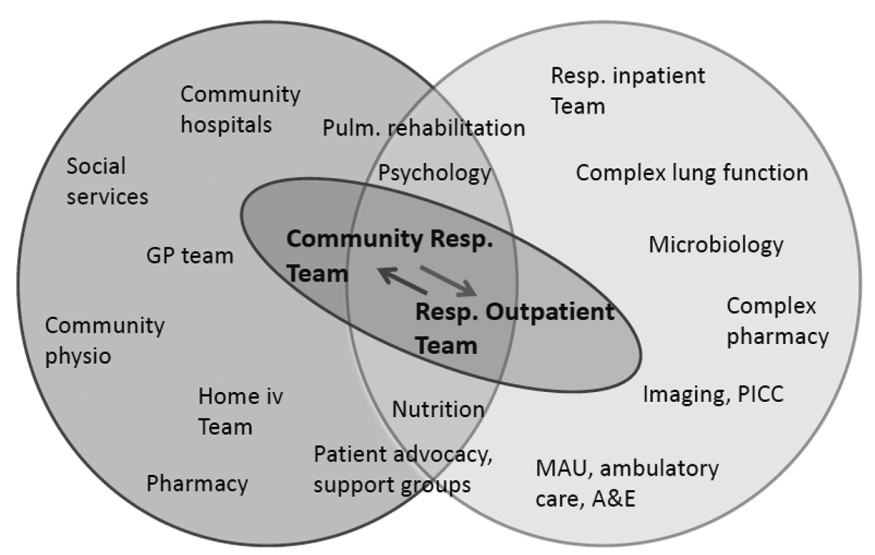

Abstract P95 Figure 1 